\title{
SCHOOL CULTURE, PRACTICES AND STRUCTURE AS PREDICTORS OF PERFORMANCE OF SECONDARY SCHOOL STUDENTS IN EDO STATE, NIGERIA
}

\author{
Omaze Anthony Afemikhe1i, \\ Kennedy Imasuen, \\ Vivian Ozofu Idusogie ${ }^{2}$ \\ ${ }^{1}$ Institute of Education, \\ University of Benin, \\ Benin City, Nigeria \\ ${ }^{2}$ Department of Educational Evaluation \\ and Counselling Psychology, \\ University of Benin, Benin City, \\ Nigeria
}

\begin{abstract}
:
Quality in education can be seen as fitness for purpose and one indicator of this is the quality of the learning environment within the school system. At play in this environment are factors of school culture, practice and structure and one measure of the quality of schools is students' performance. The relationship between each of these factors and performance has been variously investigated but their combined predictive ability of performance does not seem to have been examined in the literature. This is the focus of the study. The survey design was utilized in the study. The population consists of all the 1700 teachers in Edo State, Nigeria who teach in the three hundred and nine public senior secondary schools. Out of the schools, 62 schools representing 20\% of the schools were selected. From the schools selected, five teachers each of whom teach English Language, Mathematics, Economics, Biology and Christian Religious Studies were selected to provide the information. On the whole, 285 teachers returned usable questionnaires. The draft questionnaire adapted from those constructed earlier by Gruenert and Valentine (1998) was composed of four sections, namely personal information of the teachers, School structure, school practices and school culture. The questionnaire was given to five experts knowledgeable in assessment, educational management and experienced senior secondary school principals. These experts were expected to examine the items on the questionnaire to ensure that they were adequate in content, comprehension and readability. Based on their comments, the items were modified and the resulting instrument was administered to 30 teachers outside the sample used in the study for purposes of determining the reliability using Cronbach alpha. The reliability coefficients
\end{abstract}

'Correspondence: email tonyafemikhe@yahoo.co.uk 
that emerged were $.78, .83$ and .75 for school culture, school structure and school practice respectively. Cooperation of Principals of the schools selected for the study was solicited for the administration of the questionnaire and making available records of WASSCE results for their schools for the year 2018. The performance of the school was calculated by finding a weighted mean for the grades obtained by the students who sat for the WASSCE in each of the subjects and cumulated across the school subjects for each school. Multiple regression was used in the analysis at 5\% level of significance. School culture was related to performance while school practice and structure were not. In addition, the three factors were useful in jointly predicting performance in schools. It was therefore recommended that schools should examine these factors properly if they intend to shore up their performance.

Keywords: school structure, school practices and school culture, multiple regression, Nigeria

\section{Introduction}

School quality is normally measured with respect to outcomes as related to teachers and to students. While teacher outcomes could focus on satisfaction with teaching, ability to accomplish instructional goals with their students, teacher commitment and morale; student outcomes, obviously and principally are concerned with academic achievement, measured by student performance on standardized achievement tests. Teachers teach and students learn within the school in a context that is generally referred to as the learning environment. In exploring the quality of the school, an economic and sociological strands have been found useful. The economic framework focused on school effectiveness utilizing a production function of the input-output design. This involved monetization of inputs such as teachers' salaries, class size, books in the library among others and finding out their impact on the achievement of students. The sociological perspective is based on issues of social stratification. and interest in "effective schools" with a tilt toward the larger institutional and societal structures that surround schools and the organizational properties that characterize them. This later component constitutes the learning environment which is affected to a great extent by the external environment of schools; the issues of interest include the types of students who attend, school size, and the nature of parental involvement. These are influential in determining a school's internal operations and willy nilly also have some direct effects on teachers and students.

Within the learning environment are school culture, structure and practices. According to Kaplan et al. (2013), school culture encompasses the shared orientations, values, norms, and practices with which an educational unit are held together, giving it a distinctive identity, and vigorously resist any change from the outside which may want to influence how things are done within the organization. For Fullan (2007), school culture can be defined as the guiding beliefs and values evident in the way a school 
operates; it indeed covers all the attitudes, expected behaviours and values as they impact on how the school operates. Schein (1985:6) considers the basic essence of the culture of an organization to be, "the deeper level of basic assumptions and beliefs that are shared by members of an organisation, that operate unconsciously, and that define in a basic 'taken-forgranted' fashion an organisation's view of itself and its environment". Kaplan et al. (2007:1) posits that "Just as water surrounds fish, shaping their world view and influencing where they swim, culture surrounds and envelopes principals, teachers, students, and parents, shaping their perspectives and influencing their beliefs, assumptions, decisions, and actions."

School culture is discernible in many aspects of school life: safe and caring environment, classroom support that is welcoming and valued by students and high values of learning and behaviour are cherished. Others include traditions and routines based on shared values that reinforce the school's academic, ethical, and social standards, teachers and students have a voice in making decisions as they affect the learning environment. Partnerships involving parents, businesses, and community organizations to support students' learning and character growth are in place in addition to acceptable norms of professional culture of excellence and ethics. School culture can benefit or do harm; strong culture can reduce ambiguity, increase commitment and consistency of staffers, and hence all efforts are directed toward a desired common goal. Through this, there is an increase in the scope, depth, complexity, and success of attainment by both teachers and students. In some organizations, the culture could be toxic with the people feeling not valued and considered only as valuable as their production, the consequence is that culture becomes a liability as the shared values are not in agreement with those that will advance the school's goals and effectiveness.

Within schools, there is a classroom culture that prescribes the principal's leading role that eventuates in learning outcomes. This environment is inductively influenced by the school culture, community culture and societal/national culture according to Cheong (2000). As indicated by Deal et al. (2002), for school culture to contribute to improved student learning it requires a focus on learning, collaboration, a focus on SMART goals and timely and relevant information.

The school structure is a conglomeration of plans for the operations of a school towards the attainment of high standards of learning for all students. It encompasses the size of the school, course offerings, class formation procedures, grouping practices, resource allocations among others in driving the school's activities towards its mission and vision. The structure reflects elements of the equitable environment, shared vision, mission, belief, autonomy and a personalized environment. In fact, a conducive and personalized environment, school-based decision-making, implementing continuum classes, monitoring students' progress and extra-curricular activities are important components of the school structure. The school structure is the epitome of school bureaucracy. How the structure helps or hinders the operations of the school has been utilized to conceptualize it as a continuum. At one end the school structure is enabling and at the other end, it is hindering. 
The enabling school structure helps; it has a system of rules and regulations that guides problem-solving and provides principals and teachers with the opportunity to work cooperatively across recognized authority boundaries while retaining their distinctive roles. Similarly, rules and regulations are flexibly guides for problem-solving and whatever hierarchy and rules exists are only in place to support teachers rather than vehicles to enhance principal power. According to Wu et al. (2013) the enabling school structure is the perception in which leadership promotes innovation, collaboration, and trust among participants and the flexible rules and procedures to promote problemsolving.

The hindering school structure is a direct opposite of the enabling one as it impedes and utilizes rules and regulations that are coercive. The basic objective of hierarchy is the disciplined compliance of teachers. Within this structure, teacher behaviour must be closely managed and the hierarchy and rules are used to gain conformity. Indeed, rules and regulations are used to buttress administrative control, which, in turn, typically hinders the effectiveness of teachers. Hierarchy and rules within the hindering structure are to assure that reluctant, incompetent, and irresponsible teachers do what administrators prescribe. Thus, change and problem-solving are prevented from occurring and the control of the organization is pursued in an unyielding, autocratic approach that discourages the member participation as teachers perceive that they have no voice in the decision. The power of the principal is enhanced, but the work of the teachers is diminished. Trust is important in schools; teachers must trust their principal and each other. As summarized by Hoy et al. (2001: 314) "enabling schools encourage trusting relationships between teachers and between teachers and the principal". Hindering schools would eventuate in the opposite.

School practices are the events employed by school administrators to improve students' learning; they help learners learn successfully. Auerbach (2002) identified a common core of practices that any successful leader falls back on to include setting directions, developing people and redesigning the organization. In fact, Ronald et al. (2006) have indicated that factors like discipline, challenging curriculum, tracking and teaching performance depend on the organizational practices and can influence students' success. Some school practices that go hand-in-hand with a high level of students' performance which can be shaped by good policy and effective leadership are the allocation of time and space, feedback and reinforcement.

The effect of strong school culture has been reflected in better-motivated teachers who have greater success in terms of student performance and student outcomes. Hence MacNeil et al., (2009) have suggested that school principals seeking to improve student performance should focus on improving the school's culture by getting the relationships right between themselves, their teachers, students and parents. This relationship is what has been seen as school practice. The findings of the study by MacNeil et al., (2009) suggest that students achieve higher scores on standardized tests in schools with healthy learning environments. Badri, et al. (2014), Bhengu et al. (2014), Scheerens et al. (2013) and Vadi (2007) have opined that improving school effectiveness which is a fundamental 
aim for teachers, leaders, and societies could be affected by a number of factors including school culture. School culture is really critical because it shapes teacher-student interaction as well as interaction among teachers (Powers, 2009). Badri et al. (2014), Karadag et al. (2014) and Melesse et al. (2018) have found that school culture influence students' academic achievement. Teachers perceive their school to be more effective if they are involved in shared decision-making and collegial relationships, professional activity is encouraged, and the rules of the organization are more formalized (Gray, 2011). Emunemu et al. (2014) found elements of school culture to be related to performance among Nigeria students.

From the foregoing, it can be indicated that school culture, practices and structure are important variables that may affect quality education. However, their relative importance has not been investigated. Furthermore, assessment of the effect of these variables has most often been based on students' responses. Therefore, it is imperative to find out the extent to which these variables from the perspective of teachers predict the performance of students in secondary schools. Consequently, the following research questions were addressed:

1) What is the relationship between each of school culture, practices and structure and performance in secondary schools in Nigeria?

2) How do school culture, practices and structure predict performance in secondary schools in Nigeria?

\section{Methodology}

\subsection{Design}

The descriptive research design was adopted for the collection of the information.

\subsection{Population and Sample}

In Edo state, there are three hundred and nine public senior secondary schools. The population of teachers in public senior secondary schools was 1700 teachers. From the schools selected, five teachers each of whom teach English Language, Mathematics, Economics, Biology and Christian Religious Studies were selected to provide the information.

\subsection{Instruments}

The instruments used for data collection were a questionnaire and records of West African Senior School Certificate Examination (WASSCE) results for English Language, Mathematics, Economics, Biology and Christian Religious Studies. The questionnaire was composed of four sections. The first requested for the personal information of the teachers such as age, age, location and gender. Section B focused on School structure, section $C$ was on school practices and section $D$ was on school culture. The response options for sections B and D were 'rarely', 'sometimes', 'often' and 'very frequently' while that for section $\mathrm{C}$ were 'not at all', 'once in a while', 'sometimes', 'often' and 'very 
frequently'. A draft copy of the questionnaire was adapted from those constructed earlier by Gruenert et al. (1998). The questionnaire was given to five experts knowledgeable in assessment, educational management and experienced senior secondary school principals. These experts were expected to examine the items on the questionnaire to ensure that they were adequate in content, comprehension and readability. Based on their comments, the items were modified and the resulting instrument was administered to 30 teachers outside the sample used in the study for purposes of determining the reliability using Cronbach alpha. The reliability coefficients that emerged were $.78, .83$ and .75 for school culture, school structure and school practice respectively.

\subsection{Data Collection}

As part of data collection, a letter was written to principals of the secondary schools selected for the study soliciting their cooperation in the administration of the questionnaire to the teachers in the school and making available records of WASSCE results for their schools for the year 2018.

\subsection{Data Analysis}

The performance of the school was calculated by finding a weighted mean for the grades obtained by the students who sat for the WASSCE in each of the subjects. These were then cumulated across the school subjects. The retrieved usable questionnaires were scored and the scores on each item were cumulated to get scores for each of school culture, school structure and school practice. Scores on school culture, school practice and school structure were then subjected to Pearson product-moment correlation to determine the relationship between each of school culture, school structure and school practice and academic performance. Linear multiple regression was used to determine the extent to which school culture, school structure and school practice predict academic performance. The analysis was executed at 5\% significance level.

\section{Results}

Table 1 presents the correlation between performance and each of School structure, School culture and School practice. The correlations between school structure and performance $(\mathrm{r}=.017, \mathrm{p}=.772)$ and school practice and performance $(\mathrm{r}=.000, \mathrm{p}=.998)$ were not significant at $5 \%$ significance level. It is only the relationship between school culture and performance $(\mathrm{r}=-.208, \mathrm{p}=.000)$ which is significant. The negative sign of the relationship is indicative of the inverse relationship between school culture and performance. The $\mathrm{r}^{2}$ which is indicative of how much of performance is accounted for by the school culture gave a value of .043 ; thus, only 4.3 percent of this variation is actually accounted for. 
Table 1: Correlation between performance and each of School Structure, School Culture and School Practice

\begin{tabular}{|l|l|c|}
\hline \multirow{4}{*}{ School Structure } & & Performance \\
\hline \multirow{5}{*}{ School Culture } & Pearson correlation & .017 \\
\cline { 2 - 3 } & Sig. (2-tailed) & .772 \\
\cline { 2 - 3 } & $\mathrm{N}$ & 285 \\
\hline \multirow{3}{*}{ School Practice } & Pearson correlation & -.208 \\
\cline { 2 - 3 } & Sig. (2-tailed) & .000 \\
\cline { 2 - 3 } & $\mathrm{N}$ & 285 \\
\hline & Pearson correlation & .000 \\
\cline { 2 - 3 } & Sig. (2-tailed) & .998 \\
\cline { 2 - 3 } & $\mathrm{N}$ & 285 \\
\hline
\end{tabular}

Table 2 contains the summary of the regression statistics. The multiple $\mathrm{R}$ value of .217 indicates the correlation between the predictor variables (School structure, School culture and school practice) and the criterion variable (performance). R Square of .047 indicated how well the model or regression line fits the data; $4.7 \%$ of the variation in unit performance is explained by all the predictor variables. The adjusted R square of .037 is as a result of the inflation emergent from the multiple regression analysis.

Table 2: Regression Summary

\begin{tabular}{|l|c|}
\hline Regression Statistics \\
\hline Multiple R & $217^{\mathrm{a}}$ \\
\hline R Square & .047 \\
\hline Adjusted R Square & .037 \\
\hline Standard Error & 3.789 \\
\hline a. Predictors: (Constant), School practice, School culture, School structure \\
\hline
\end{tabular}

The ANOVA summary component in Table 3 yielded an $F(3,281)=4.611, p=.004$. Thus, the regression equation is able to predict the performance of the learners. A consideration of the unstandardized coefficients shows that if the effect of the predictors were annulled the performance would be 24.032. The coefficients for School culture (-.053) and school practice (-.020) are indicative that a unit increase in these variables will lead to a decrease in the value of the performance. The predictor which is most efficacious is school culture $(\beta=-.225)$ while the least one is school structure $(\beta=.012)$. Thus, school culture makes a contribution that is about 19 times that of the school structure. The $t$-values for the predictors were School structure $(t=.153, \mathrm{p}=.879)$, School culture $(-3.698, \mathrm{p}=.000)$ and school practice $(t=-.916, p=.360)$ and it is only that of school culture that is significant at $5 \%$. 


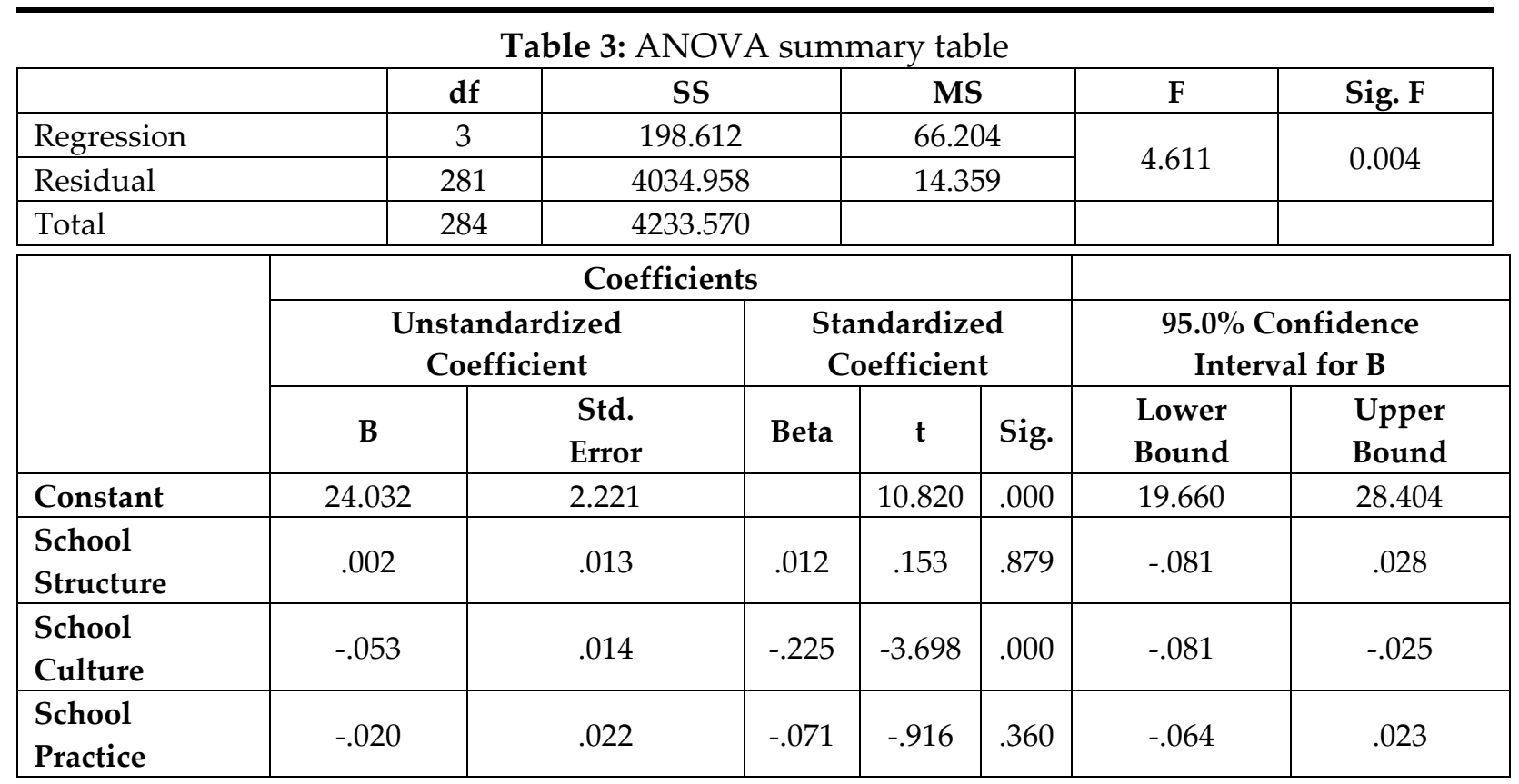

a. Dependent Variable: Performance

\section{Discussion of Results}

The fact that school culture generally was related to performance is not unexpected as school culture has been seen as really critical because it shapes teacher-student interaction as well as interaction among teachers (Powers, 2009; Badri et al., 2014); Karadag et al., 2014). The negative sign of the relationship is worrisome though as this would tend to indicate that as the school culture is toxic, then performance improves. The findings by Melesse et al. (2018) which showed that school culture influence students' academic achievement, therefore, does not corroborate those of the present study. Neither those of Emunemu et al. (2014), who found elements of school culture to be related to performance among Nigeria students. The results of this study also did not find any relationship between school practice and performance. It is possible that the teachers were not sufficiently involved in shared decision-making, a professional activity not given necessary impetus, and the rules of the organization were not more formalized (Gray, 2011). This is likely in this era where budgetary allocation to education in Nigeria is low and teacher supply in many schools is in short supply. The absence of no significant relationship between each of school structure and school practice with performance is at variance with the benefits expected from these factors within the learning environment. Thus discipline, challenging curriculum, tracking and teaching performance that depend on the organizational practices for improved performances in schools are possibly not well implemented.

As only $4.7 \%$ of the variation in performance was explained by the predictor variables of school culture, school practice and school structure, that points to the existence of other important factors that influence the performance of the learners. The amount of performance predicted was however not by chance thus signifying that these 
factors are important in improving performance in secondary schools in Nigeria. These are however not the subject of this study.

\title{
5. Conclusion and Recommendations
}

It can be concluded from this study that among the factors investigated, school culture was most potent in its relationship with performance. Furthermore, a linear combination of all three factors was useful in predicting the performance of secondary school students. Consequently, it is recommended that the school culture within schools that mirrors that of the community in which the school is located has to be properly monitored to ensure it yields the desired results. Schools must equally look inwards at their school practices and structure to ensure they become enabling so that they can shore up the performance of the learners.

\section{Acknowledgement}

This work was financially supported by Tertiary Education Trust Fund (TETFUND) Nigeria (2018) Research Project (RP) Intervention (Batch 13) for the University of Benin, Benin City.

\begin{abstract}
About the Authors
Omaze Anthony Afemikhe is a professor of Educational Evaluation, a member of the Nigerian Academy of Education and a former Director, Institute of Education, University of Benin, Benin City. He teaches courses in Statistics, Research, and Assessment related courses.
\end{abstract}

Kennedy Imasuen is a lecturer at the University of Benin, Benin City, Nigeria. His background is Industrial Mathematics, Measurement and Evaluation and teaches Mathematics-related courses in Early Childhood Education, Research, and Measurement and Evaluation.

Vivian Ozofu Idusogie is a lecturer at the University of Benin, Benin City, Nigeria. She has a B. Sc Agricultural Education and a PhD in Measurement and Evaluation. She teaches courses in Research and Statistic, Measure and Evaluation.

\section{References}

Angus J. MacNeil, Doris L. Prater \& Steve Busch (2009). The effects of school culture and climate on student achievement, International Journal of Leadership in Education, 12:1,73-84, DOI: 10.1080/13603120701576241

Badri, R., Amani-Saribaglou, J., Ahrari, G., Jahadi, N. \& Mahmoudi, H. (2014). School culture, basic psychological needs, intrinsic motivation and academic achievement: Testing a casual model. Mathematics Education Trends and Research, 2014, 1-13. doi:10.5899/2014/metr-00050

Bhengu, T. T. \& Mthembu, T. T. (2014). Effective leadership, school culture and school 
effectiveness: A case study of two 'sister' schools in Umlazi Township. Journal of Social Sciences, 38(1), 43-52. DOI:10.1080/09718923.2014.11893235

Cheong, C. Y. (2000). Cultural factors in school effectiveness: a framework for comparative work, School Leadership and Management 20(2) 207-225.

Deal, K. D. and Peterson, T. E. (2002). Shaping School Culture Field book. San Francisco, CA: The Jossey-Bass Education Series.

Emunemu, B. O., Adu, E. O., \& Yusufu, I. O. (2014). The Influence of Selected Elements of Schools Culture on Students' Academic Performance in Southwestern Nigeria. The Ghana Journal of Development Studies, 11:1, 58-77. DOI:10.4314/gjds.v11i1.4

Fullan, M. (2007). The new meaning of educational change (4th ed.). New York: Teachers College Press.

Gray, J. A. (2011). Professional learning communities and the role of enabling school structures and trust. Published doctoral dissertation. University of Alabama, Tuscaloosa, AL.

Hoy, W. K., \& Sweetland, S. (2001). Designing better schools: The meaning and measure of enabling school structures. Educational Administration Quarterly, 37(3), 296321.

Kaplan, L. S. and Owings, W. A. (2013). Culture re-boot: reinvigorating school culture to improve student outcomes. Thousand Oaks, California: Corwin, a SAGE company.

Karadağ, E., Kiliçoğlu, G and Yilmaz, D. (2014). Organizational Cynicism, School Culture, and Academic Achievement: The Study of Structural Equation Modeling. Educational Sciences: Theory \& Practice, 14(1), 102-113. DOI: 10.12738/estp.2014.1.1640

Melesse, S. \& Molla, S. (2018). The contribution of school culture to students' academic achievement: The case of secondary and preparatory schools of Assosa Zone, Benshangul Gumuz Regional state, Ethiopia. Research in Pedagogy, 8, 2, 190-203. DOI: $10.17810 / 2015.83$

Powers, J. M. (2009). Charter schools: From reform imagery to reform reality. New York, Palgrave Macmillan. doi:10.1057/9780230622111_1

Scheerens, J., Witziers, B. \& Steen, R. (2013). A meta-analysis of school effectiveness studies. Revista de Educacion, 2013(361), 619-645. doi:10.1080/13803611.2012.718485

Schein, E. H. (1985). Organizational culture and leadership. San Francisco: Jossey-Bass.

Vadi, M. (2007). Relationships between organizational culture and performance in Estonian schools with regard to their size and location. Baltic Journal of Economics, 1, 3-17. doi:10.1080/1406099x.2007.10840438

Wu, J. H., Hoy, W. K., \& Tarter, C. J. (2013). Enabling school structure, collective responsibility, and a culture of academic optimism: Toward a robust model of school performance in Taiwan. Journal of Educational Administration,51(2), 176193. 

to copy, distribute, transmit or adapt the article content, providing a proper, prominent and unambiguous attribution to the authors in a manner that makes clear that the materials are being reused under permission of a Creative Commons License. Views, opinions and conclusions expressed in this research article are views, opinions and conclusions of the author(s). Open Access Publishing Group and European Journal of Education Studies shall not be responsible or answerable for any loss, damage or liability caused in relation to/arising out of conflicts of interest, copyright violations and inappropriate or inaccurate use of any kind content related or integrated into the research work. All the published works are meeting the Open Access Publishing requirements and can be freely accessed, shared, modified, distributed and used in educational, commercial and non-commercial purposes under a Creative Commons Attribution 4.0 International License (CC BY 4.0). 